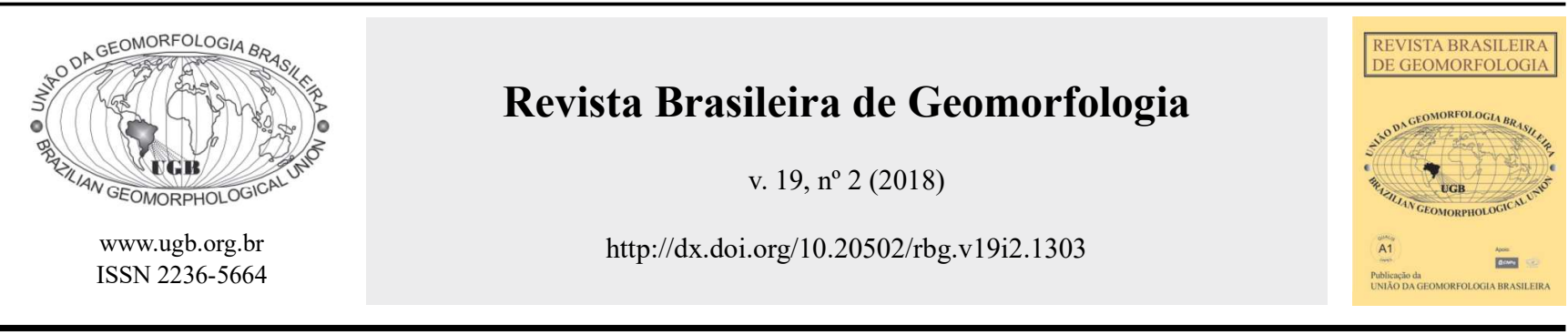

\title{
INFLUÊNCIA DO CULTIVO DE CANA-DE-AÇÚCAR NAS PERDAS DE SOLO POR EROSÃO HÍDRICA EM CAMBISSOLOS NO ESTADO DE SÃO PAULO
}

\section{INFLUENCE OF SUGARCANE CULTIVATION ON SOIL LOSSES BY WATER EROSION IN INCEPTSOLS IN SÃO PAULO STATE}

\author{
Edvania Aparecida Corrêa \\ Departamento de Geografia, Universidade Federal de Pelotas \\ Rua Almirante Barroso, 1202, Pelotas, Rio Grande do Sul. CEP: 96010-280. Brasil \\ Email: edvania.correa86@gmail.com \\ Isabel Cristina Moraes \\ Departamento de Geografia, Universidade de Brasília \\ Campus Universitário Darcy Ribeiro, Brasilia, Distrito Federal. CEP: 70910-900. Brasil \\ Email:bel.moraes@gmail.com \\ Cenira Maria Lupinacci \\ Departamento de Planejamento Territorial e Geoprocessamento, Universidade Estadual Paulista \\ Av. 24a 1515 , Rio Claro, São Paulo. CEP: 13506-900. Brasil \\ Email: cenira@rc.unesp.br \\ Sérgio dos Anjos Ferreira Pinto \\ Departamento de Planejamento Territorial e Geoprocessamento, Universidade Estadual Paulista \\ Av. 24a 1515 , Rio Claro, São Paulo. CEP: 13506-900. Brasil
}

Email:sanjos@rc.unesp.br

Informações sobre o Artigo

Recebido (Received):

28/08/2017

Aceito (Accepted):

$22 / 10 / 2017$

Palavras-chave:

Solos arenosos; Quantificação de perda de solo; NDVI.

\section{Keywords:}

Sandy soils; Quantification of soil loss; NDVI.

\section{Resumo:}

Considerando o destaque do estado de São Paulo na produção sucroalcooleira do país, o objetivo deste trabalho foi o de avaliar a interferência do cultivo de cana-de-açúcar nas perdas de solo por erosão hídrica em Cambissolos de textura franco arenosa do leste paulista. Para quantificar as perdas foram utilizadas 4 parcelas de monitoramento, localizadas na bacia hidrográfica do ribeirão Monjolo Grande, pertencente à bacia do rio Corumbataí. Para avaliar o vigor vegetativo, foram obtidos valores de NDVI em diferentes estágios de crescimento da cana e em parcelas desprovidas de cobertura vegetal. Ao longo do ano experimental set/2013 a set/2014, a erosividade registrada de $4546,8 \mathrm{MJ} / \mathrm{ha} /$ ano foi responsável por perdas totais de 74,03 e 206,53 $\mathrm{t} \mathrm{ha}^{-1}$ ano $^{-1}$ nas duas parcelas de solo exposto e de 49,04 e 84,85 t ha ${ }^{-1}$ ano $^{-1}$ nas duas parcelas de cana. A coincidência entre os períodos chuvosos e a ausência de cobertura dos solos na entressafra e estágios iniciais de plantio agrava os processos erosivos. Os maiores teores de areia fina e declives superiores a $12 \%$ indicaram maior suscetibilidade erosiva. As condições 
de limitação hídrica e/ou deficiência nutricional comprometeram o desenvolvimento vegetativo, reduzindo a proteção dos solos. Os resultados reforçam a necessidade de adequação das práticas de uso da terra na área de estudo.

\begin{abstract}
:
Considering the importance of São Paulo state in the sugarcane production in Brazil, the objective of this work was to evaluate the interference of this cultivation in soil losses by water erosion in Inceptisols with sandy loam texture from the east of São Paulo. To quantify the soil losses it was used four monitoring plots, located in the catchment area of the Monjolo Grande creek, belonging to the Corumbataí river basin. To evaluate the vegetative vigor, values of NDVI were obtained in different stages of sugarcane growth and in plots lacking vegetation cover. During the experimental year Sep/2013 to Sep/2014, the erosivity of $4546.8 \mathrm{MJ} / \mathrm{ha} /$ year was responsible for total losses of 74.03 and $206.53 \mathrm{t} \mathrm{ha}^{-1}$ year ${ }^{-1}$ in the two plots of exposed soil, and 49.04 and $84.85 \mathrm{tha}^{-1}$ year-1 in the two sugarcane plots. The coincidence between the rainy periods and the absence of cover in the off-season and in the initial stages of plating aggravate the erosive processes. The highest levels of fine sand and declining higher than $12 \%$ indicated greater erosive susceptibility. The conditions of water limitation and nutritional deficiency compromised the vegetative development, reducing soil protection. The results confirm the need to adapt land use practices in the study area.
\end{abstract}

\section{Introdução}

Li et al. (2009) apontam que a erosão hídrica é uma das maiores causas da degradação dos solos devido à remoção da camada superior do solo, a qual apresenta maior concentração de matéria orgânica e nutrientes. Quanto às principais implicações desta degradação, destacam-se a diminuição dos estoques de carbono no solo e impactos aos efeitos do aquecimento global, a redução da quantidade e da atividade da fauna do solo e a contaminação e assoreamento de reservatórios e cursos d'água. No geral, observa-se que a taxa de formação dos solos em áreas agrícolas é inferior à taxa de remoção, e, em escala global, verifica-se uma drástica redução da qualidade do solo, desencadeando no abandono de áreas agrícolas e no declínio da produção de alimentos (MONTGOMERY, 2007).

Em escala mundial, apesar das inumeráveis consequências ao meio ambiente e à economia, constata-se a concentração espacial de estudos científicos experimentais referentes à erosão hídrica do solo, conforme apontado por Martin e Minella (2013) e por Garcia Ruiz et al. (2015). Garcia Ruiz et al. (2015) concluíram que, no geral, a América do Norte e a Europa retêm o maior número de estudos experimentais relacionados à estimativa de perdas de solo em comparação com o número de trabalhos realizados na América do Sul. Consequentemente, em determinadas regiões do globo, os dados presentes sobre erosão dos solos são impróprios devido à utilização de modelos preditivos calibrados para regiões e escalas inadequadas (BOARDMAN, 2006). Conforme Garcia Ruiz et al. (2015), o limitado conhecimento sobre as taxas de formação dos solos e sobre a dinâmica erosiva torna incerta a análise da sustentabilidade dos solos.

A retirada da cobertura vegetal natural pela ação antrópica é um dos principais fatores aceleradores do processo erosivo. Nesse caso, o aumento das taxas de erosão hídrica do solo é influenciado pelo uso desordenado da terra e a adoção de práticas inadequadas de conservação do solo ou ausência dessas. A este respeito, Mendes (1993), Fiorio et al. (2000), Martinelli e Filoso (2007), Merten e Minella (2013) afirmam que, em cultivos de cana-de-açúcar no cenário nacional, há evidências científicas de processos de degradação do solo.

Conforme dados apresentados pela UNICA (2015), nos últimos 10 anos, a cultura de cana-de-açúcar apresentou expansão de $94 \%$ de área plantada no estado de São Paulo, com consequente diminuição das áreas de pastagens. Apesar de esta cultura ser considerada semi-perene, na qual a reforma das áreas cultivadas se dá em ciclos de aproximadamente cinco anos, tem-se a coincidência do período de entressafra com os períodos de maiores índices pluviométricos, em que o solo se encontra apenas parcialmente protegido por cobertura vegetal. Segundo a CONAB (2012), o estado de São Paulo é o maior produtor sucroalcooleiro do país, sendo que em 2012 tal estado dominava $51,82 \%$ de toda a produção nacional. No entanto, nos canaviais paulistas, 
Sparovek e Schnug (2001) estimaram perdas de solo de 31 t.ha $^{-1} \cdot$ ano $^{-1}$ por erosão hídrica. Neste sentido, a existência e a expansão da indústria canavieira devem ser avaliadas com cautela, prevenindo-se problemas ambientais superiores aos proventos econômicos (MARTINELLI e FILOSO, 2007).

Dentro deste cenário, os produtos de técnicas de sensoriamento remoto possuem elevada importância nos estudos ambientais visto a possibilidade de coleta de dados em diferentes épocas, viabilizando análises dos fenômenos sinopticamente através do tempo (VALENTE, 2001). Na avaliação de alvos vegetais, os índices de vegetação proporcionam a análise da cobertura vegetal, possibilitando a mensuração e quantificação das condições em que os mesmos se encontram. Também é possível, através destes mesmos índices, a compreensão das características biofísicas e estruturais dos alvos vegetais (BINDER et al.,2009; NERY et al., 2014). No contexto da erosão hídrica dos solos, a análise das condições de cobertura vegetal realizada a partir dos índices de vegetação auxilia na compreensão dos processos de degradação do solo.

Considerando o destaque do estado de São Paulo na produção sucroalcooleira do país, o objetivo deste trabalho foi o de avaliar a interferência do cultivo de cana-de-açúcar nas perdas de solo por erosão hídrica em Cambissolos de textura franco arenosa do leste paulista. Foram utilizadas parcelas experimentais para quantificar as perdas, sendo estas localizadas na bacia hidrográfica do ribeirão Monjolo Grande. Foram obtidos valores de NDVI para o cultivo de cana-de-açúcar e solo desprovido de vegetação visando avaliar a interferência das condições da cobertura vegetal nas perdas de solo. A avaliação do comportamento erosivo em Cambissolos foi delineada devido à permissão do uso de propriedades agrícolas, bem como a representatividade desta unidade na área de estudo e a pré-disposição natural destes solos frente aos processos de erosão hídrica.

\section{Caracterização da Área de Estudo}

$\mathrm{Na}$ bacia hidrográfica do córrego Monjolo Grande foram instaladas as parcelas experimentais de monitoramento de erosão, denominadas de $\mathrm{C} 1$ e $\mathrm{C} 2$ para as áreas com cana-de-açúcar, e SD1 e SD2 para as áreas desprovidas de vegetação. Esta bacia localiza-se no município de Ipeúna, centro leste do estado de São
Paulo - Brasil, sendo tributária do rio Passa Cinco, pertencente à bacia hidrográfica do rio Corumbataí, e compreendendo área aproximada de $28 \mathrm{~km}^{2}$ (Figura 1).

Conforme a classificação zonal de Köppen, o clima da área de estudo está enquadrado no tipo climático Cwa, sendo este associado ao clima subtropical, com verão chuvoso e inverno seco.

A área de estudo está localizada na transição entre as áreas de relevo de Cuestas arenito-basálticas e a província geomorfológica da Depressão Periférica Paulista, zona do Médio Tietê. Tal região apresenta um relevo erodido, muito diversificado, e com estruturas resistentes observáveis em ressaltos topográficos. O relevo é predominantemente formado por colinas, cujas altitudes variam de $550 \mathrm{~m}$ a $600 \mathrm{~m}$. Por estar inserida em uma zona de transição, apresenta drenagem densa e entalhada, áreas de elevada declividade e formas de relevo residual como os Morros da Guarita e do Bizigueli. Tais relevos residuais são feições características das áreas de transição entre a Depressão Periférica Paulista e o relevo de cuestas arenito-basálticas (Figura 2a), os quais apresentam-se como pequenos maciços residuais de front da cuesta arenito-basálticas, cujas altitudes máximas são de 900 metros (ALMEIDA, 1964).

Tem-se o predomínio de Argissolo Vermelho Amarelo nas altas, médias e baixas vertentes, com declividades de até $20 \%$ e de Neossolos Quartzarênicos nas áreas de interflúvios (Figura 2b). Os Cambissolos ocorrem maioritariamente nas áreas de média e baixa vertente e próximos aos canais de drenagem e cujas declividades variam de 15 a 45\%. Tais unidades são observadas junto ao front das cuestas arenito-basálticas e também na zona de transição com a depressão periférica. Nos locais próximos ao front das cuestas arenito-basálticas e nas áreas com declives superiores a $45 \%$ e localizadas ao longo dos canais de $1^{a}$ ordem da zona de transição com a depressão periférica paulista, observa-se a presença de Neossolos Litólicos (CORRÊA, 2016; MORAES, 2016).

Os solos da área de estudo possuem textura variando de arenosa a média, sendo originados maioritariamente dos arenitos das formações Piramboia e Botucatu. Corrêa et al. (2015), avaliando a predisposição natural à erosão, verificaram que $40 \%$ da área da bacia com perdas acima de 100 ton.ha ${ }^{-1}$.ano ${ }^{-1}$. Tais áreas encontram-se localizadas em relevos ondulados a fortemente ondulados e com declives maiores que $8 \%$. 
Estado de São Paulo/Brasil

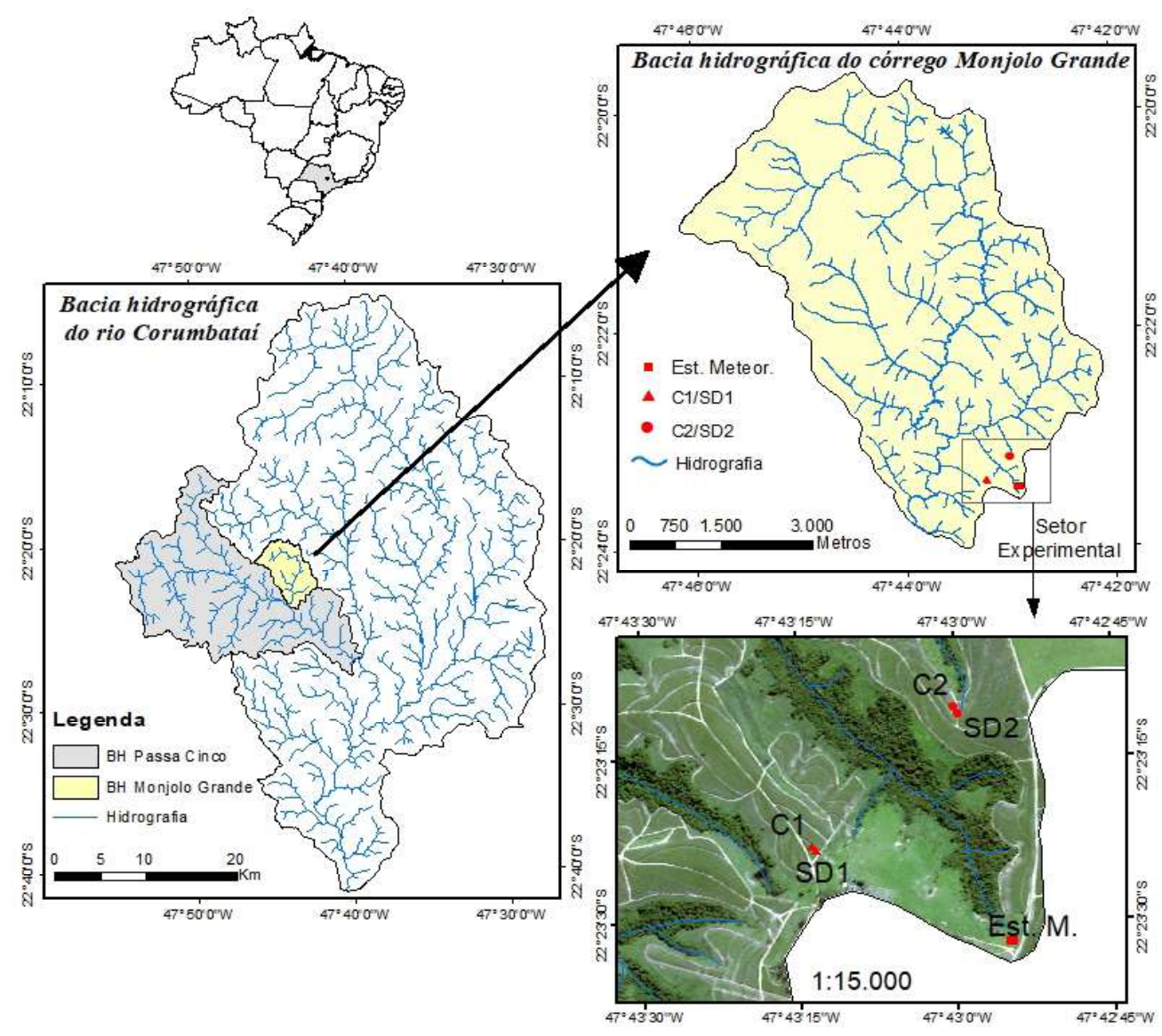

Figura 1 - Localização da área de estudo.

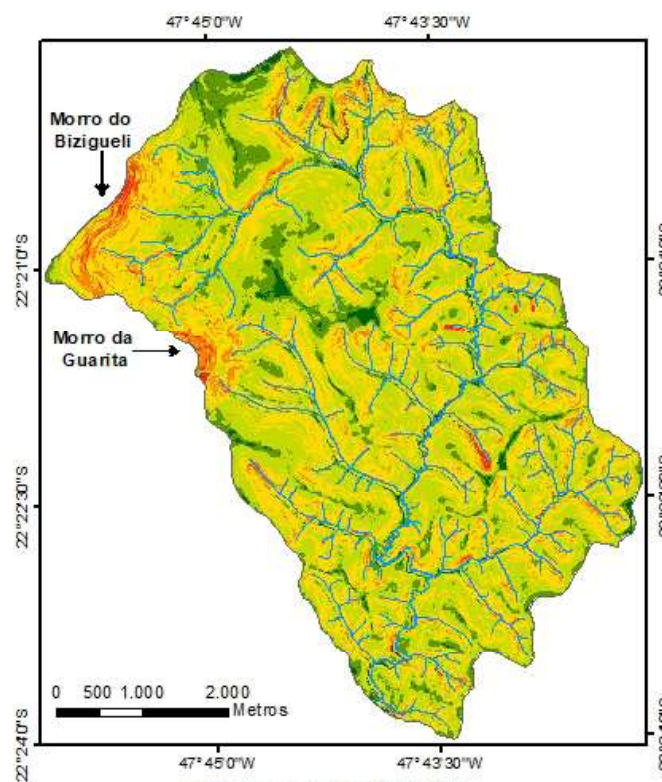

Classes de declividade (\%)

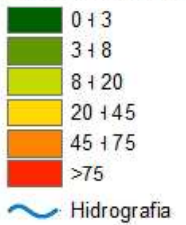

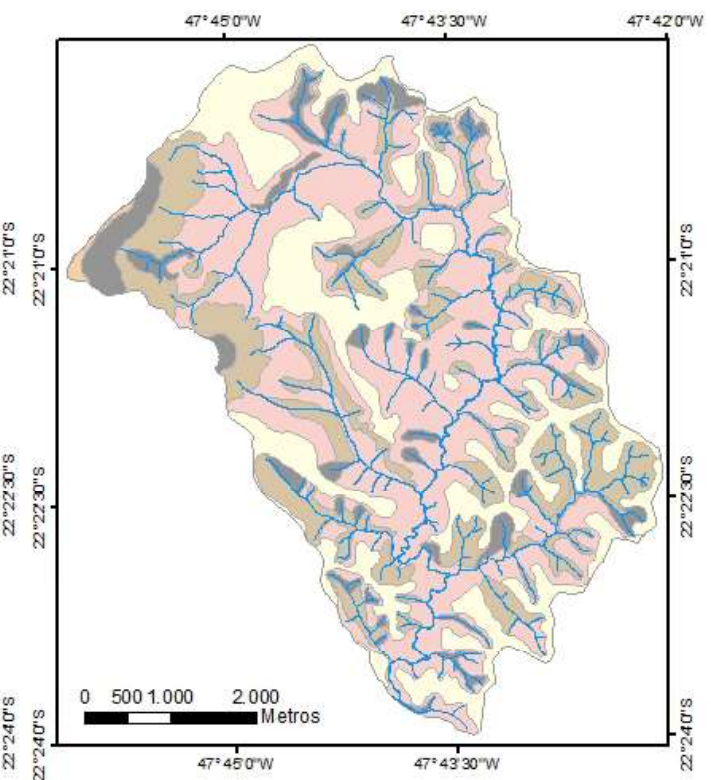

Legenda

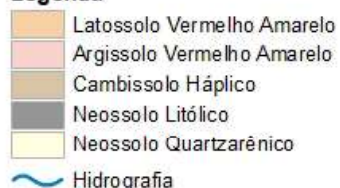

Figuras $2 a$ e $2 b$ - Classes de declividade e de solo presentes na bacia hidrográfica do córrego Monjolo Grande. 
Koffler (1993) e Pereira e Pinto (2007) indicam que em todo o estado de São Paulo há uma intensa expansão das áreas de cana-de-açúcar e de pastagens. Neste contexto, Corrêa et al. (2015) identificaram, no período de 1988 a 2013, expansão de $80 \%$ dos canaviais na bacia hidrográfica do córrego Monjolo Grande. Tal expansão ocorreu em locais inadequados à culturas anuais e de maior suscetibilidade à erosão hídrica do solo, especialmente em áreas de maiores declividades e na presença de solos de elevada erodibilidade, como Argissolos Vemelho Amarelos e Cambissolos.

De acordo com Corrêa (2016), as unidades de Cambissolos na bacia do ribeirão Monjolo Grande apresentam evidências de processos erosivos acelerados, como horizontes superficiais decapitados, principalmente nos setores com uso da terra por cana-de-açúcar realizado por aproximadamente 10 anos de uso consecutivo. Assim, o estudo em Cambissolo contribui para a compreensão da dinâmica erosiva nestes cultivos.

\section{Metodologia}

Para a implantação das parcelas experimentais de monitoramento de erosão do solo foram selecionados locais com as classes de declives de maior abrangência espacial e coincidentes com áreas usadas com canade-açúcar. Também, devido à permissão de uso de propriedades agrícolas particulares, todas as parcelas foram implantadas em Cambissolo háplico, Ta eutrófico, típico, A moderado, textura franco arenosa, por ser esta uma unidade taxonômica de significativa representatividade na bacia. Foram instaladas 4 parcelas de $20 \mathrm{~m}^{2}$ (2,00 x 10,00 metros), obedecendo o sentido do declive, e delimitadas por chapas galvanizadas de $40 \mathrm{~cm}$ de altura, sendo $10 \mathrm{~cm}$ introduzidos no solo e o restante acima da superfície. Também foram compostas pela calha de Gerlach (GUERRA, 2005) e por tanques armazenadores de água.

As parcelas experimentais com cana-de-açúcar, denominadas $\mathrm{C} 1$ e $\mathrm{C} 2$, foram instaladas em declividade de $12 \%$ e de $15 \%$, respectivamente (Figura 3 ). Visando avaliar a proteção oferecida pela cultura de cana-deaçúcar, também foram implantadas parcelas desprovidas de vegetação, denominadas SD1 e SD2, implantadas em declividade variando de $12 \%$ e de $15 \%$, respectivamente.

As parcelas foram implantadas após o plantio da cana-de-açúcar (26/07/2013). O plantio foi realizado em 22/07/2013, com variedades de cana ciclo médio (variedade RB 966928), em sistema convencional de preparo do solo, com gradagem pesada, intermediária e niveladora, e práticas conservacionistas de direcionamento de água dos caminhos para terraços, construção de terraços e plantio em curva de nível. Foram mantidos poucos restos vegetais dos cultivos anteriores na superfície. A colheita ocorreu manualmente devido às condições de declividade do terreno.

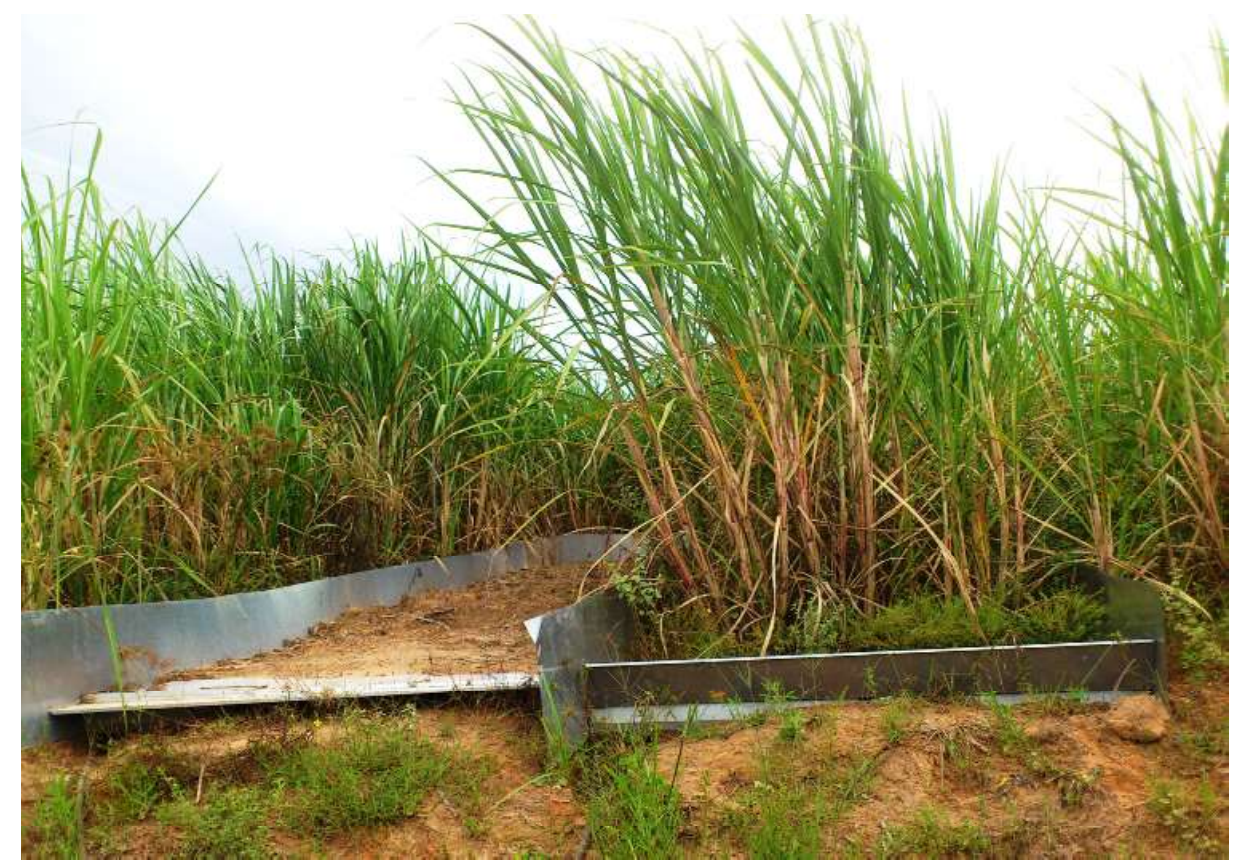

Figura 3 - Parcelas de monitoramento de erosão desprovidas de vegetação e com cultura de cana-de-açúcar-C1 e SD1 (Fonte: Edvania Ap. Corrêa). 
Após a implantação das parcelas, o monitoramento foi realizado ao longo de 1 ano, sob condições de chuva natural. Em função das parcelas experimentais localizarem-se em terrenos particulares, não foi possível a replicação dos experimentos ou dilatação do período experimental. Uma vez que, idealmente, os experimentos de campo devem ser conduzidos por longos períodos de tempo sob condições de chuva natural (WISCHMEIER e SMITH, 1958), optou-se por dar ênfase em análises de eventos específicos de chuva, descartando-se os primeiros eventos erosivos, dada a instabilidade dos agregados pelo próprio processo de instalação das parcelas.

Após cada evento chuvoso, foram realizadas coletas. Todo sedimento retido nas calhas coletoras foi adicionado ao material armazenado nos tanques coletores e posteriormente foi realizada a homogeneização de todo o material (sedimento e água). Ainda em campo, foram colhidas amostras do material homogeneizado (aproximadamente $500 \mathrm{ml}$ ) e registradas as alturas das enxurradas no interior dos tanques armazenadores de água $(\mathrm{cm})$, pela inserção do metro rígido. Assim, tendo as dimensões dos tanques conhecidas, foram computados os valores do volume de água obtidos por escoamento superficial de cada parcela.

Com o objetivo de quantificar as perdas de solo, principalmente no que se refere ao material inorgânico, a quantificação do material oriundo do processo erosivo foi realizada pelo método da evaporação (CARVALHO et al., 2000). Visando à decantação do sedimento, todas as amostras ficaram em repouso por 24 horas. $\mathrm{O}$ líquido excedente foi passado em peneira de $0,052 \mathrm{~mm}$. Visando à evaporação e secagem do sedimento, o material restante foi levado à estufa em temperatura de $60^{\circ}$. Os valores de perdas e solos em cada parcela foram quantificados após a secagem das amostras, sendo considerado o volume total de água nos tanques. Os valores de perdas de solo em cada parcela foram comparados com os valores de tolerância de perdas de solo presentes em Mannigel et al (2002).

As informações de precipitação foram coletadas em intervalos de 5 minutos, a partir dos registros obtidos pela estação meteorológica modelo Davis Vantage Pro 2 Plus, instalada a cerca de $400 \mathrm{~m}$ das parcelas $\mathrm{C} 1 \mathrm{e}$ SD1 e $650 \mathrm{~m}$ das parcelas $\mathrm{C} 2 \mathrm{e} \mathrm{SD} 2$. Para expressar o potencial erosivo das chuvas, Wischmeier e Smith (1958, apud BERTONI e LOMBARDI NETO, 2010) correlacionam a energia cinética por sua intensidade máxima em 30 minutos, determinando as chuvas erosivas.
Com base em Wischmeier (1959) e Lombardi Neto (1977), foram selecionadas as chuvas erosivas e obtida a energia cinética das gotas de chuva (BERTONI e LOMBARDI NETO, 2010):

$$
E_{C}=0,119+0,0873 \log I
$$

sendo:

$E_{C}=$ energia cinética em Megajoule/ha-mm;

$I=$ intensidade da chuva em $\mathrm{mm} / \mathrm{h}$.

A intensidade máxima em 30 minutos $\left(\mathrm{I}_{30}\right)$ foi determinada para cada chuva erosiva, conforme Wischmeier e Smith (1978). Para cada evento erosivo, foi selecionado o índice de erosividade o qual foi obtido a partir da proposta de Bertoni e Lombardi Neto (2010):

$$
E I_{30}=E_{C} \times I_{30}
$$

sendo:

$E I_{30}=$ índice de erosão em $\mathrm{MJ} / \mathrm{ha} \cdot \mathrm{mm} / \mathrm{h}$;

$E_{C}=$ energia cinética da chuva;

$I_{30}=$ intensidade máxima em 30 minutos $(\mathrm{mm} / \mathrm{h})$.

A erosividade mensal e anual foi obtida a partir da somatória da erosividade de todas as chuvas consideradas erosivas.

Foram feitas sondagens com trado e coletadas amostras de solo de cada parcela experimental nas profundidades de 0 a $60 \mathrm{~cm}$, conforme a Embrapa (1999). As análises granulométricas foram realizadas pelo método da Pipeta (EMBRAPA, 1997). Também foram feitas as análises químicas: $\mathrm{pH} \mathrm{em} \mathrm{CaCl}^{2}, \mathrm{Al}$, $\mathrm{H}+\mathrm{Al}, \mathrm{K}, \mathrm{Ca}$ e $\mathrm{Mg}$ trocáveis calculando-se soma de bases (SB), capacidade de troca catiônica a $\mathrm{pH} 7$ (CTC), saturação por bases (V\%) e por alumínio (m\%) e matéria orgânica (EMBRAPA, 1997). Foi realizada a classificação dos solos conforme o Sistema Brasileiro de Classificação dos Solos (EMBRAPA, 2013), em nível de Subgrupo $\left(3^{\circ}\right.$ nível), mais grupamento textural. Ainda em campo, foi realizada a análise da estrutura do solo a partir da visualização e descrição dos perfis.

Também foram obtidos os valores de densidade do solo (método do torrão parafinado), macro e microporosidade (método da mesa de tensão) e porosidade total (EMBRAPA, 1997).

Foram adquiridas imagens orbitais do sensor MS/ Ikonos nas datas de 01/08/13 e 24/10/2013. Tal sensor 
possui resolução espacial de 4,0 metros e 4 bandas espectrais, sendo as bandas do Azul $(0.445-0.516 \mu \mathrm{m})$, Verde $(0.506-0.595 \mu \mathrm{m})$, Vermelho $(0.632-0.698 \mu \mathrm{m}) \mathrm{e}$ Infravermelho próximo $(0.757-0.853 \mu \mathrm{m})$. Também foram adquiridas imagens do sensor MS/GeoEye nas datas de 20/11/2013 e 23/04/2014. Este sensor possui resolução espacial de 1,65 metros e também apresenta 4 bandas espectrais (Azul - 0.450-0.510 $\mu \mathrm{m}$; Verde

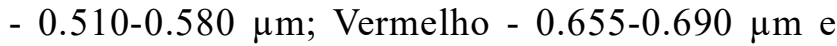
Infravermelho próximo - 0.780-0.920 $\mu \mathrm{m})$. Todos os procedimentos de pré-processamento e processamento das imagens brutas foram realizados no software ENVI 5.0. Quantos aos procedimentos, destacam-se a calibração radiométrica, ortorretificação, mosaico e correção atmosférica (módulo QUAC). Considerando a análise temporal dos alvos, foi realizada a retificação radiométrica conforme proposto por Hall et al. (1991), tendo como referência o cenário de novembro/2013. Foram adquiridos os índices de vegetação pela diferença normalizada (NDVI), conforme Rouse et al. (1973). Foi realizada a média dos valores de NDVI referentes aos pixels de cada parcela e para cada cenário avaliado.

\section{Resultados e Discussão}

$\mathrm{Na}$ análise granulométrica, todos os solos das parcelas apresentaram valores maiores que $70 \%$ de areia total e superiores a $45 \%$ de areia fina (Tabela 1 ).

Tabela 1: Características granulométricas e relação textural dos solos contidos nas parcelas de monitoramento de erosão

\begin{tabular}{ccccccc}
\hline Parcelas & Profundidade & Areia Grossa & Areia Fina & Silte & Argila & Relação textural \\
\cline { 1 - 3 } & $\mathrm{cm}$ & - & - & - & & \\
& $0-20$ & 23,4 & 55,2 & 5,5 & 16,0 & $<1,5$ \\
& $20-40$ & 25,2 & 52,2 & 4,5 & 18,2 & \\
& $40-60$ & 26,3 & 48,7 & 4,2 & 20,8 & \\
C2 e SD2 & $0-20$ & 10,6 & 80,3 & 5,2 & 4,0 & $>2,5$ \\
& $20-40$ & 8,5 & 66,1 & 2,4 & 23,0 & \\
& $40-60$ & 8,9 & 63,4 & 3,4 & 24,3 & \\
\hline
\end{tabular}

Em consequência da textura média arenosa a arenosa, os solos apresentam maior quantia de macroporos e menor de microporos. Tais atributos condicionam: elevada aeração; pouca ou nenhuma coesão entre as partículas; maior condutibilidade hidráulica; drenagem rápida; e pequena capacidade de retenção de água de nutrientes e matéria orgânica (Tabelas 1 e 2).

Tabela 2: Atributos físicos e teor de matéria orgânica dos solos presentes nas parcelas de monitoramento de erosão do solo.

\begin{tabular}{lcccccccc}
\hline & Densidade & $\begin{array}{c}\text { Macro } \\
\text { porosidade }\end{array}$ & $\begin{array}{c}\text { Micro } \\
\text { porosidade }\end{array}$ & $\begin{array}{c}\text { Porosidade } \\
\text { total }\end{array}$ & $\begin{array}{c}\text { Prof. } \\
\text { efetiva }\end{array}$ & $\begin{array}{c}\text { Matéria } \\
\text { orgânica }\end{array}$ & $\begin{array}{c}\text { Permeabilidade } \\
\text { (p) }\end{array}$ & RMP \\
\hline & $\mathrm{kg} / \mathrm{dm}^{3}$ & $--------\mathrm{m}^{3} / \mathrm{m}^{3}-------$ & $\mathrm{dm}^{3} / \mathrm{dm}^{3}$ & $\mathrm{~mm}$ & $\mathrm{~g} \cdot \mathrm{kg}$ & $\mathrm{mPa}$ \\
\hline $\mathrm{C} 1$ e SD1 & 1,51 & 0,3 & 0,13 & 0,42 & 700 & 1,8 & 0,8 & 2,25 \\
$\mathrm{C} 2$ e SD2 & 1,49 & 0,24 & 0,21 & 0,45 & 700 & 1,8 & 0,8 & 3,02 \\
\hline
\end{tabular}

Os solos também apresentaram pobreza em alguns nutrientes como o cálcio $(\mathrm{Ca})$, pouca matéria orgânica, e elevada acidez trocável por alumínio $(\mathrm{m} \%)$ (Tabela 3 ). Por serem solos de textura franco arenosa, indicam elevada suscetibilidade à erosão hídrica por causa da elevada porcentagem de areia muito fina e fina além da fraca agregação em composição. Solos que apresentem tais condições precisam de cuidados quanto à reposição de nutrientes e matéria orgânica nas práticas de preparo e conservação do solo (MEDEIROS, 2006). A maior suscetibilidade ao destacamento de frações de areia fina pode ser constatada na figura 4 . 
Tabela 3: Análise química dos solos contidos nas parcelas de monitoramento de erosão.

\begin{tabular}{|c|c|c|c|c|c|c|c|c|c|c|c|c|c|}
\hline Parcelas & $\mathbf{P}$ & $\mathbf{K}$ & $\mathrm{Ca}$ & Mg & Al & $\mathbf{H}+\mathbf{A l}$ & MO & CT & SB & CTC & $\mathbf{V}$ & $\mathbf{m}$ & pH \\
\hline & $\mathrm{mg} \cdot \mathrm{dm}^{-3}$ & \multicolumn{5}{|c|}{ mmolc. $\mathrm{dm}^{-3}$} & \multicolumn{2}{|c|}{ g.kg } & \multicolumn{2}{|c|}{ mmolc.dm ${ }^{-3}$} & \multicolumn{2}{|c|}{$\%$} & $\mathrm{CaCl}_{2}$ \\
\hline C1 e SD1 & 83 & 7,3 & 25 & 8 & 8,5 & 22 & 18 & 10,6 & 40 & 63 & 64 & 17 & 5,6 \\
\hline $\mathrm{C} 2$ e SD2 & 17 & 2,4 & 10 & 3 & 0 & 28 & 18 & 10,4 & 15 & 44 & 35 & 0 & 4,7 \\
\hline
\end{tabular}

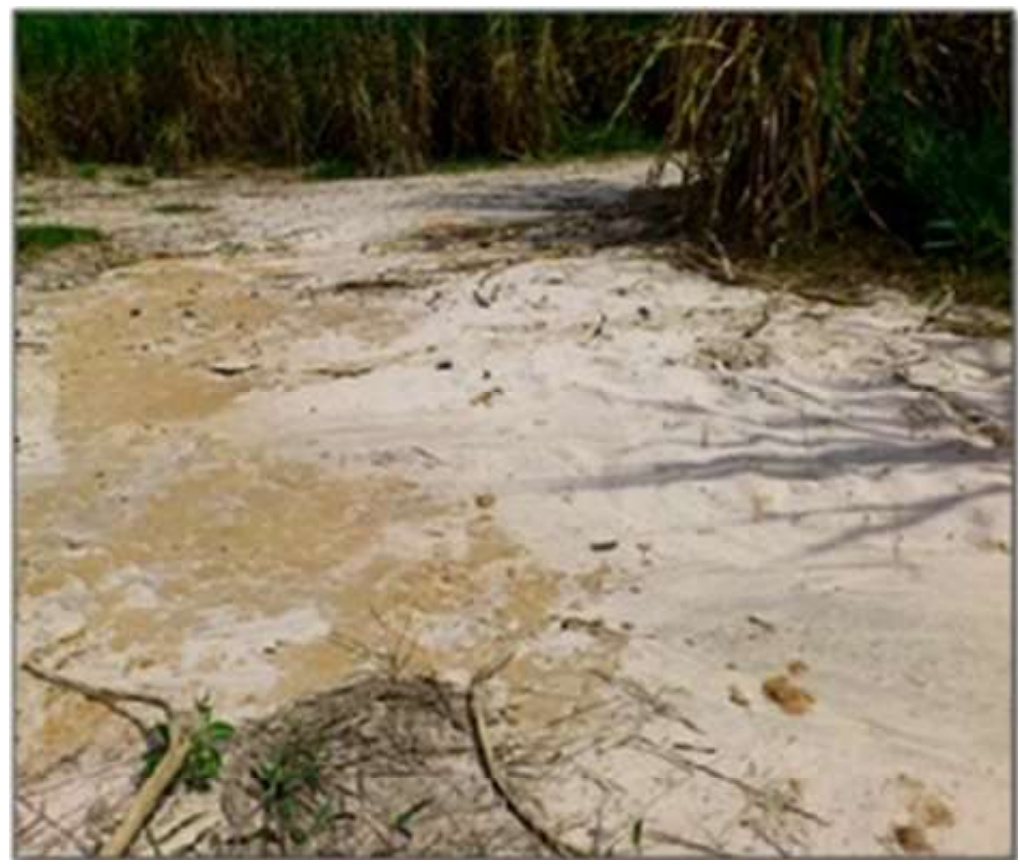

Figura 4 - Destacamento de partículas de frações de areia fina. (fonte: Edvania Aparecida Corrêa).

A erosividade registrada na safra 2013/2014, referente ao período de setembro de 2013 a setembro de 2014 , foi de $4546,8 \mathrm{MJ} / \mathrm{ha} / \mathrm{ano}$, valor este inferior à média estimada por Lombardi Neto et al. (1980). Tais autores, determinando a erosividade média anual das chuvas no estado de São Paulo/Brasil, apresentaram que na área de estudo a erosividade média anual variou de 6750 a $7000 \mathrm{MJ} / \mathrm{ha} /$ ano.
A chuva é um dos elementos climáticos de maior relevância na erosão hídrica dos solos (BERTONI e LOMBARDI NETO, 2010). Neste sentido, as maiores taxas de erosividade coincidem com as maiores perdas de solo, dados os registros dos meses de outubro e novembro de 2013 e janeiro de 2014 (Figura 5). Aliada a tais fatores, a condição erosiva agrava-se devido à menor quantidade de cobertura vegetal do solo, dada pelo NDVI (Figuras 6 e 7).

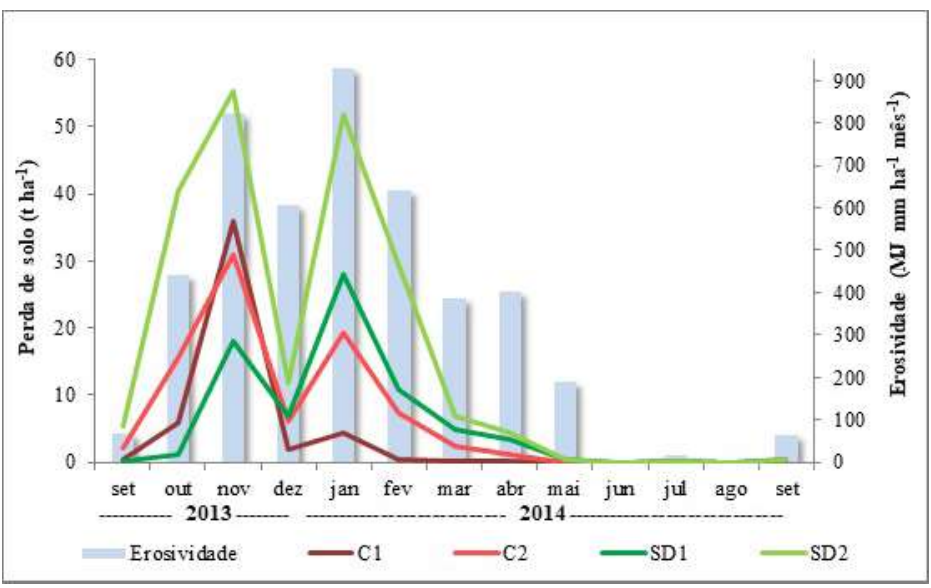

Figura 5 - Erosividade e perdas de solo no periodo de 2013/2014. 


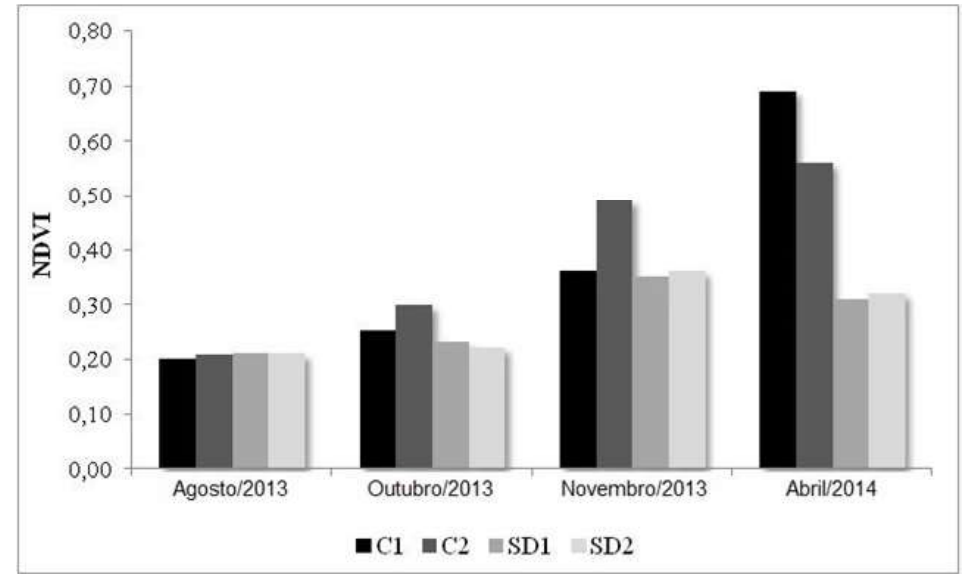

Figura 6. NDVI médio das parcelas de erosão do solo.
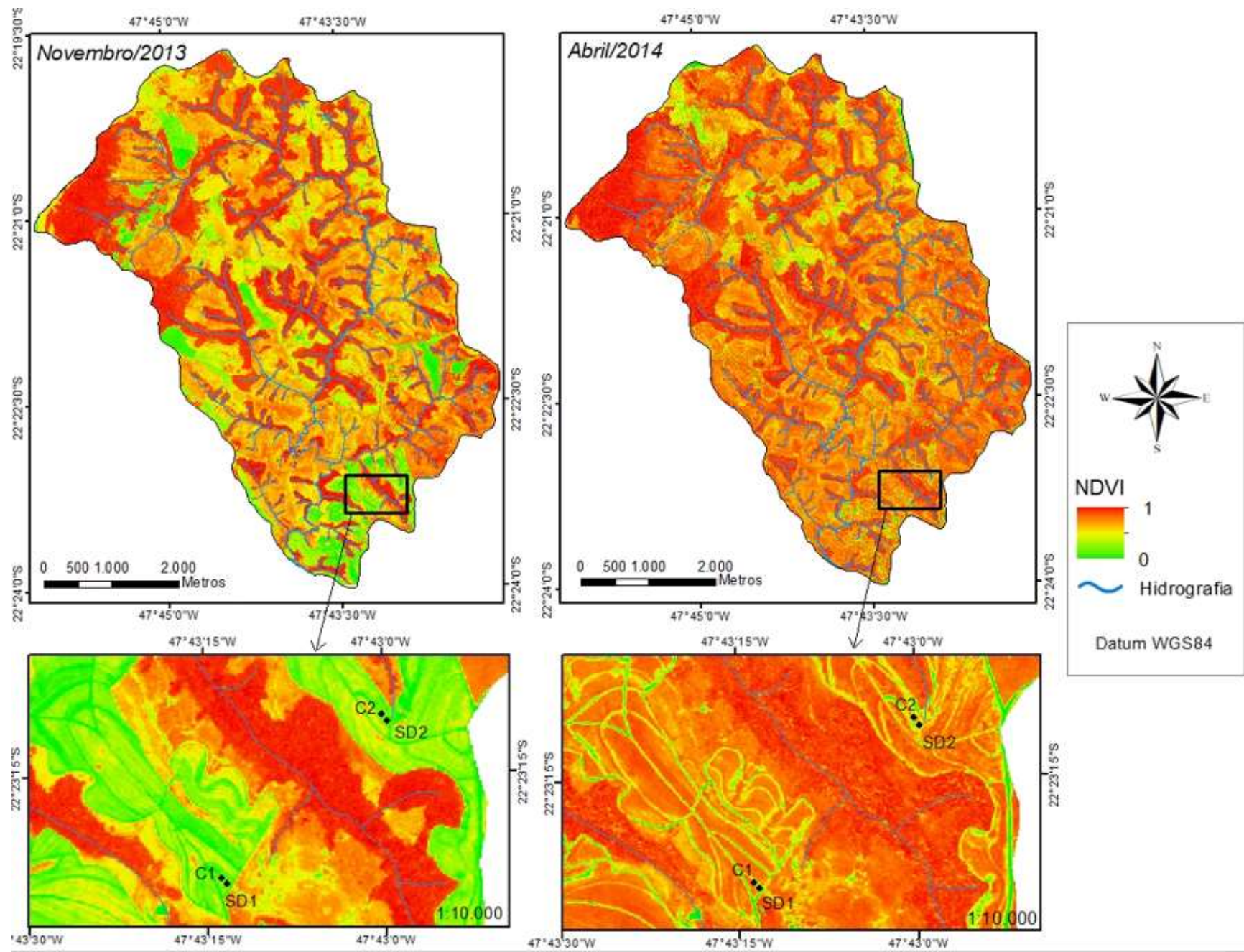

Datum WGS84

Figuras 7 a e 7 - Imagens NDVI dos cenários de novembro/2013 e abril/2014.

Ao longo do ano experimental, as perdas totais de solo foram de 49,04 e 74,03 tha ${ }^{-1}$ ano $^{-1}$ nas parcelas C1 e SD1, e de 84,85 e 206,53 tha ${ }^{-1}$ ano $^{-1}$ nas parcelas C2 e $\mathrm{SD} 2$, respectivamente. A interferência da cobertura vegetal é indicada pela comparação entre as parcelas de cana-de- açúcar e de solo exposto, pois as perdas obtidas foram menores entre 1,5 e 2,5 vezes nas parcelas com cultivo.

A maior quantidade de areia fina e os baixos teores de matéria orgânica fazem com que as partículas do solo sejam menos estáveis à ação de destacamento 
das gotas de chuvas (Tabela 1). Também, a baixa profundidade efetiva e a declividade superior a $6 \%$ favorecem o aumento do escoamento superficial bem como o transporte de partículas.

Assim, a partir da comparação entre as parcelas, C2 e SD2 apresentaram as maiores perdas registradas. Além das maiores declividades, entre 12 e $20 \%$, estas parcelas apresentam média de $70 \%$ de areia fina no perfil de solo em comparação aos $52 \%$ das parcelas $\mathrm{C} 1$ e SD1, fatores que proporcionaram as maiores perdas registradas. A maior relação textural entre o horizonte superficial e o subsuperficial dos Cambissolos nas parcelas C2 e SD2 $(>2,5)$, em relação às parcelas $\mathrm{C} 1$ e SD1 $(<1,5)$, favorece a redução da capacidade de infiltração de água entre os horizontes do solo.

Além disto, solos que apresentam maior fração de areia e menor de matéria orgânica possuem menor capacidade de armazenamento de água. Essas condições resultam em menor disponibilidade de água e nutrientes à vegetação e impedimento do pleno desenvolvimento vegetal. Neste sentido, a vegetação também pode apresentar dificuldade no desenvolvimento, do sistema radicular (em profundidade e extensão) devido às condições de fertilidade natural, baixa retenção de água e aeração. Consequentemente, nas estações de estiagem, tais condições promovem o estresse hídrico e o limitado desenvolvimento e produtividade nas plantas (KIEHL, 1979).

Este fato pode ser evidenciado com os valores de NDVI obtidos para os cenários de agosto, outubro e novembro de 2013 e abril de 2014, conforme as figura 6 e 7 Para avaliar a proporção do desenvolvimento vegetativo da cana-de-açúcar, verificou-se que: de agosto a outubro de 2013, os valores de NDVI aumentaram $30 \%$ para $\mathrm{C} 1$ e $50 \%$ para $\mathrm{C} 2$; de outubro para novembro de 2013, aumentaram $35 \%$ para $\mathrm{C} 1 \mathrm{e}$ $60 \%$ para C2; e de novembro de 2013 para abril de 2014, aumentaram $100 \%$ para $\mathrm{C} 1$ e apenas $12 \%$ para $\mathrm{C} 2 . \mathrm{Na}$ média dos cenários avaliados, o NDVI cresceu $165 \%$ para $\mathrm{C} 1$ e $122 \%$ para $\mathrm{C} 2$.

Especialmente entre o cenário de novembro de 2013 para abril de 2014, os valores de NDVI da parcela $\mathrm{C} 2$ apresentam menor proporção de crescimento vegetativo $(12 \%)$ em comparação à parcela $\mathrm{C} 1$ $(100 \%)$, e, portanto, tem-se menor quantidade e vigor da vegetação. Tais características sugerem limitação hídrica e/ou deficiência nutricional em função dos maiores teores de areia fina, menores taxas de matéria orgânica, maior declividade e dificuldade de manutenção de água no perfil. Por consequência, e associados às condições físico-químicas dos solos e estiagem atípica, os Cambissolos da parcela $\mathrm{C} 2$ estavam mais suscetíveis aos processos erosivos devido à menor proteção pela vegetação.

Esta constatação se deu pela análise dos eventos de chuva erosiva em 31/03, 01/04 e 09/04, quando se registraram erosividades de 136,4, 146 e 84,9 MJ/ ha.mm/h (Figura 8). O total da erosividade destes eventos, de $367 \mathrm{MJ} / \mathrm{ha} . \mathrm{mm} / \mathrm{h}$, foi responsável pelas perdas de 4,7 e $84,4 \mathrm{~g} / \mathrm{m}^{2}$ para $\mathrm{C} 1$ e $\mathrm{C} 2$, e de 338,6 e $478,7 \mathrm{~g} / \mathrm{m}^{2}$ para SD1 e SD2, respectivamente. É notória a maior suscetibilidade erosiva nas parcelas C2 e SD2 em função das condições físico-químicas do solo e maiores declives. No entanto, os valores de NDVI obtidos em abril foram de 0,7 para $\mathrm{C} 1$ e de 0,55 para $\mathrm{C} 2$, evidenciando a interferência de maior fator de cobertura vegetal e vigor vegetativo na proteção dos solos a processos erosivos.

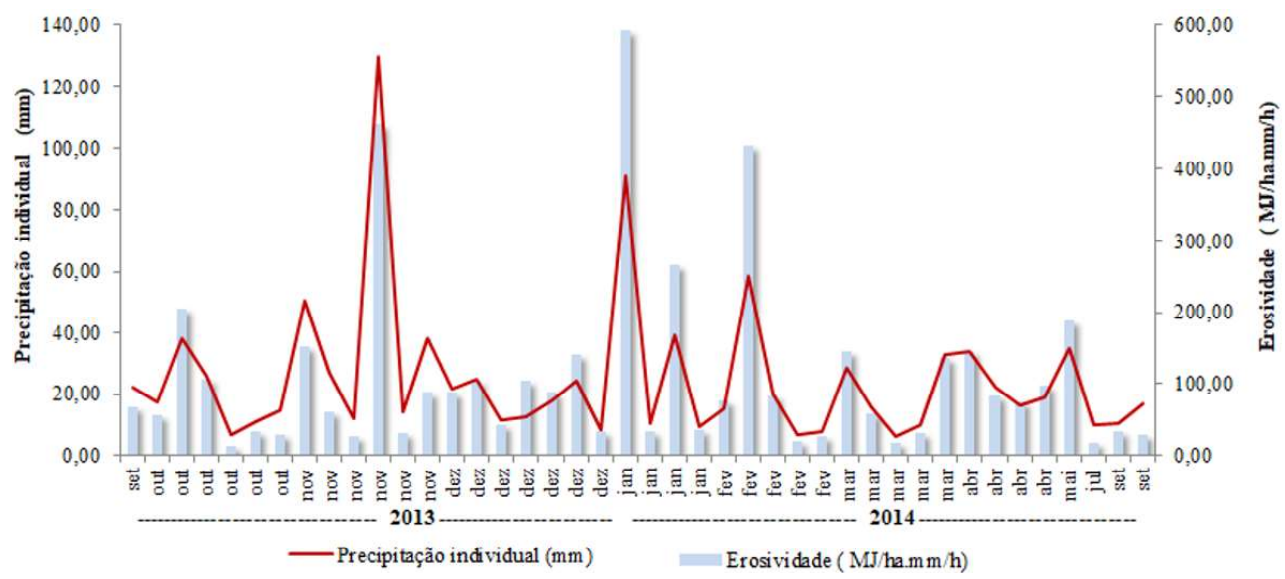

Figura 8 - Precipitações individuais e correspondentes valores de erosividade de todos os eventos erosivos. 
Com relação a eventos específicos de chuva erosiva, os meses de novembro de 2013 e janeiro de 2014 foram os mais expressivos. Em novembro/2013, mês com os maiores registros de perda de solo do ano experimental, destaca-se a ocorrência de dois eventos de chuva erosiva no dia $17 / 11$, os quais registraram 12,2 mm em 1:20h e $129,8 \mathrm{~mm}$ em 1:50h, ocasionando erosividade de 27,3 e 461,6 MJ/ha.mm/h, respectivamente. Estas chuvas erosivas ocasionaram perdas de 1183,42 e $721,77 \mathrm{~g} / \mathrm{m}^{2}$ para as parcelas $\mathrm{C} 1 \mathrm{e}$ $\mathrm{C} 2$, e de 2094,55 e $803,62 \mathrm{~g} / \mathrm{m}^{2}$ para as parcelas SD1 e $\mathrm{SD} 2$, respectivamente.

Entre outubro e novembro/2013, a sucessão de chuvas erosivas em dias consecutivos bem como a maior umidade antecedente favoreceram os processos erosivos. A influência da cobertura do solo foi verificada pelos valores de NDVI das parcelas $\mathrm{C} 1$ e $\mathrm{C} 2$, próximos aos obtidos nas parcelas desprovidas de vegetação. Este resultado indica baixo vigor e quantidade da vegetação e mistura espectral com o solo exposto, correspondendo ao estágio inicial do perfilhamento. Assim, houve o aumento da suscetibilidade erosiva pela menor quantidade de cobertura do solo no estágio inicial de desenvolvimento da cultura de cana-de-açúcar (Figuras 7a e 7b).

Em janeiro de 2014 evidenciam-se as chuvas erosivas registradas em 04/01 com $90 \mathrm{~mm}$ em 1:35h e 13/01 com $10 \mathrm{~mm}$ em 00:15h, resultando em erosividade de 592,2 e $34 \mathrm{MJ} / \mathrm{ha} . \mathrm{mm} / \mathrm{h}$, respectivamente. Estas chuvas erosivas ocasionaram perdas de 325,7 e 1498,6 $\mathrm{g} / \mathrm{m}^{2}$, para C1 e C2, e de 2036,9 e 3409,8 g/ $\mathrm{m}^{2}$, para SD1 e SD2, respectivamente. Em 23/01 houve chuva erosiva com 39mm em 2:30h, e em 24/01 com 9,2mm em 00:15h, cujas erosividades foram de 265,5 e $35,3 \mathrm{MJ} / \mathrm{ha} . \mathrm{mm} / \mathrm{h}$, respectivamente. Estes eventos proporcionaram perdas de 1593,6 e 4960,7 g/ $\mathrm{m}^{2}$, para C1 e C2, e de 9950,1 e $26130,0 \mathrm{~g} / \mathrm{m}^{2}$, para SD1 e SD2, respectivamente. Neste cenário, a interferência da cobertura vegetal apresentou proteção do solo 6 vezes maior na parcela $\mathrm{C} 1 \mathrm{em}$ comparação à parcela de solo exposto SD1. A cana-deaçúcar da parcela $\mathrm{C} 2$ proporcionou proteção de 2 e 5 vezes maior em comparação com a parcela desprovida de vegetação SD2.

Para os cultivos de cana-de-açúcar no cenário paulista, Bertoni el al. (1972) avaliaram perdas de solo em parcelas de monitoramento de erosão e estimaram perdas de 12,4 t ha ${ }^{-1}$ ano $^{-1}$. A partir de modelagens, Sparovek e
Schnug (2001) determinaram perdas de $31 \mathrm{t} \mathrm{ha}^{-1} \mathrm{ano}^{-1}$. Mannigel et al. (2002), avaliando a tolerância de perda de solo em Cambissolo Háplico, Tb Eutrófico, típico, de textura média, no estado de São Paulo, apresentaram limite de 11,6 tha $^{-1}$ ano $^{-1}$. A priori, quando da comparação com os resultados presentes na bibliografia, tem-se que as características de solo e relevo associadas às condições de plantio e manejo verificadas na bacia hidrográfica do córrego Monjolo Grande contribuíram para a obtenção de perdas superiores àquelas obtidas em outros cenários, extrapolando os limites indicados quanto à tolerância de perda. Tais resultados indicam a necessidade de maiores estudos visando à avaliação do comportamento erosivo de Cambissolos submetidos a cultivos de cana-deaçúcar, especialmente em áreas sujeitas aos processos de expansão de canaviais. Apesar de serem resultados primários, estes indicam a necessidade de maior cautela quanto à expansão da cana-de-açúcar em áreas de Cambissolos.

\section{Considerações Finais}

As parcelas experimentais de monitoramento erosivo, apesar de metodologia dispendiosa e que exige periodicidade quanto à obtenção dos valores de perda, contribuíram para a avaliação de perdas em Cambissolos de textura franco arenosa. A caracterização deste solo e a mensuração das perdas indicaram maior suscetibilidade erosiva em função do aumento dos teores das frações de areia fina.

A baixa profundidade efetiva, declividade superior a $12 \%$, e a maior relação textural das parcelas C2 e SD2 em comparação às parcelas $\mathrm{C} 1$ e SD1 favoreceram o aumento do escoamento superficial e o transporte de partículas. Tais características, associadas a condições físico-químicas dos solos, indicam menor capacidade de retenção de água nos perfis, comprometendo o desenvolvimento do sistema radicular e condições de fertilidade natural.

Assim, constatou-se menor desenvolvimento vegetativo da cana-de-açúcar do experimento $\mathrm{C} 2 \mathrm{em}$ relação ao $\mathrm{C} 1$, corroborado pelo menor valor de NDVI em $\mathrm{C} 2$, principalmente nos estágios entre novembro de 2013 e abril de 2014, fase de maturidade vegetal. O NDVI foi significativo para a compreensão da interferência do maior fator de cobertura vegetal e vigor vegetativo para a proteção dos solos a processos erosivos. 
Para a bacia hidrográfica do córrego Monjolo Grande, o cultivo da cana-de-açúcar deveria ocorrer em áreas naturalmente menos suscetíveis aos processos erosivos, sendo, para estas, adotadas práticas adequadas de manejo e de conservação de solo e água. Já nas áreas com Cambissolo de textura franco arenosa recomendase a alteração do uso da terra, sendo viável nestas áreas adotarem-se usos como pastagens manejadas e reflorestamento.

A combinação dos períodos mais chuvosos com a ausência de cobertura dos solos devido à entressafra e estágios iniciais de plantio agrava situações de perdas de solos em canaviais. Neste sentido, maior cautela deve ser dada quanto à expansão da cana-deaçúcar, especialmente em condições naturais de solo e relevo que sugerem suscetibilidade natural à erosão, limitação hídrica e/ou deficiência nutricional, e têm, por consequência, o comprometimento ao desenvolvimento vegetativo e, portanto, redução do fator de proteção dos solos.

\section{Agradecimentos}

À Fundação de Amparo à Pesquisa do Estado de São Paulo (FAPESP), pela bolsa de doutorado concedida e pelo apoio financeiro por meio do projeto "Avaliação da erosão hídrica, química e mecânica entre arenitos e argilitos: uma contribuição à evolução geomorfológica da bacia do Rio Corumbataí (SP)" - processo Fapesp n ${ }^{\circ}$ 2012/19935-7; à Prefeitura Municipal de Ipeúna e à Coordenadoria de Assistência Técnica Integral - CATI, pelo apoio e suporte às atividades de campo, e ao Grupo Raízen pelo apoio e concessão das áreas para a implantação dos experimentos.

\section{Referências Bibliográficas}

ALMEIDA, F. F. M. de. Fundamentos geológicos do relevo paulista. In: São Paulo. Instituto Geográfico e Geológico. Geologia do Estado de São Paulo. São Paulo. 1964. p. 169263 (Boletim n 41).

BERTONI, J.; LOMBARDI NETO, F. Conservação do solo. 7. ed. São Paulo: Editora Ícone, 2010.

BERTONI, J.; PASTANA, F.I.; LOMBARDI NETO, F.; BENATTI Júnior, R. Conclusões gerais das pesquisas sobre conservação do solo, no Instituto Agronômico de Campinas. Campinas: IAC, 1972. 56p. (Circular, 20).
BINDER, J. S.; PERES, L. F.; SANTOS, R. F. A utilização da base de dados GIMSS de NDVI no âmbito da DAS. In: Brasileiro de Sensoriamento Remoto (SBSR), 14, 2009, Natal. Anais... São José dos Campos: INPE, 2009.

BOARDMAN, J., Soil erosion science: Reflections on the limitations of current approaches. Catena, v. 68, p. 73-86.2006.

CARVALHO, N. O.; FILIZOLA JÚNIOR, N.P.; SANTOS, P.M.C.; LIMA, J.E.F.W. Guia de práticas sedimentométricas. Brasília: ANEEL. 2000. 154p.

CONAB - Companhia Nacional de Abastecimento. Levantamento de Safra 2012-2013. Disponível em: <http:// www.conab.gov.br/conteudos.php? $\mathrm{a}=1253 \mathrm{et}=2>$. Acesso em: abr.2013.

CORREA, E.A. Perdas de solo e índices de vegetação: proposta metodológica para a determinação do fator $\mathbf{C}$ (MEUPS) em pastagens e cana-d-açúcar. 2016. 187f. Tese (Doutorado em Geografia) - Universidade Estadual Paulista UNESP, Rio Claro. 2016

CORREA, E. A.; PINTO, S. dos A. F., COUTO JUNIOR, A. Espacialização temporal das perdas de solos em uma microbacia hidrográfica com predomínio de solos arenosos. Geografia, v. 40, n. 1, p. 101-118, 2015.

EMBRAPA. Centro Nacional de Pesquisa de Solos. Manual de métodos de análise de solos. 2 ed. Rio de Janeiro, 1997, 212 p.

EMBRAPA. Centro Nacional de Pesquisa de Solos. Sistema brasileiro de classificação de solos. 3 . edição. Rio de Janeiro, 2013, 353 p.

FIORIO, P. R; DEMATTE, J. A. M; SPAROVEK, G. Cronologia e impacto ambiental do uso da terra na Microbacia Hidrográfica do Ceveiro, em Piracicaba, SP. Pesquisa agropecuária brasileira, v. 35, n.4, p.671-679, 2000.

GARCÍA-RUIZ, J.M., BEGUERÍA, S., NADAL-ROMERO, E., GONZÁLEZ-HIDALGO, J. C., LANA-RENAULT, N., SANJUÁN, Y. A meta-analysis of soil erosion rates across the world. Geomorphology, v. 239, n.15, p. 160-173, 2015.

GUERRA, A. J. T. Processos erosivos nas encostas. In: CUNHA, S.B.;GUERRA, A. J. T. Geomorfologia-Exercícios, Técnicas e Aplicações. $2^{\circ}$ ed. Rio de Janeiro: Bertrand Brasil, rio de Janeiro, 2005, p. 139-155.

HALL, F.G.; STREBEL, D.E.; NICKESON, J.E.; GOETZ, S.J. Radiométric rectification: toward a common radiométric response among multidate, multisensor images. Remote Sensing of Environment, v.35, n.1, p.11-27, 1991 
KIEHL, E. J. Manual de Edafologia: Relações solo planta. São Paulo: Agronômica Ceres. 1979. 262p.

KOFFLER, N. F. Carta de declividade da bacia do Rio Corumbataí para análise digital (SIG). Geografia, Rio Claro, v. 19, n. 2. p. 167-182, 1994.

LI, L.; DU, S.; WU, L.; LIU, G. An overview of soil loss tolerance. Catena, v. 78, n. 2, p. 93-99, 2009.

LOMBARDI NETO, F. Rainfall erosivity - its distribution and relationship with soil loss at Campinas, Brasil. 1977. Dissertação (Master of Sciente) - Purdue University, West Lafayette, 1977.

LOMBARDI NETO, F.; SILVA, I. R.; CASTRO, O. M. Potencial de erosão de chuvas no Estado de São Paulo. In: Encontro nacional de pesquisa sobre conservação do solo, 3., 1980, Recife. Anais... Recife: Sociedade Brasileira de Ciência do Solo, 1980. p.159.

MANNIGEL, A. R.; CARVAlho, M. P.; MORETI, D.; MEDEIROS, L. R. Fator erodibilidade e tolerância de perda dos solos do Estado de São Paulo. Acta Scientiarum Agronomy, Maringá, v. 24, n. 5, p. 1335-1340, 2002.

MARTINELLI, L. A.; FILOSO, S. Polluting effects of Brazil's sugar-ethanol industry. Nature, v. 445, n. 364, p. 364, 2007.

MEDEIROS, J. C.; CARVALHO, M. C. S.; FERREIRA, G. B.; Cultivo do algodão irrigado. 2.ed. EMBRAPA ALGODÃO, Sistema de Produção, 2006. disponível em: <http:// sistemasdeproducao.cnptia.embrapa.br/FontesHTML/Algodao/ AlgodaoIrrigado_2ed/solos.html>. Acesso em 2 de abril de 2014.

MENDES, I. A. A dinâmica erosiva do escoamento pluvial da bacia do Córrego Lafon, Araçatuba-SP. 1993. 171 f. Tese (Doutorado em Geografia Física) - Faculdade de Filosofia, Letras e Ciências Humanas, Universidade de São Paulo, São Paulo.

MERTEN, G. H.; MINELLA, J. P. G. The expansion of Brazilian agriculture: Soil erosion scenarios. International Soil and Water Conservation Research, v. 1, n. 3, p. 37-48, 2013.

MONTGOMERY, D. R. Soil erosion and agricultural sustainability. Proceedings of the National Academy of Sciences of the USA, v. 103, n. 33, p. 13268-13272, 2007.
MORAES, I. C. Avaliação dos modelos de predição da erosão hídrica MEUPS e WEPP: contribuição em bacias hidrográficas. 2016. 191f. Tese (Doutorado em Geografia) - Universidade Estadual Paulista - UNESP, Rio Claro. 2016.

NERY, C. V. M.; MOREIRA, A. A.; FERNANDES, F. H. S.; ALMEIDA, L. S.; ALMEIDA, R. P. Utilização do modelo linear de mistura espectral e NDVI para avaliação do comportamento de área desmatada no município de Rio Pardo do Minas/MG. Revista Caminhos de Geografia, v. 15, n. 49, p. 104-112, 2014.

PEREIRA, L. H.; PINTO, S.A.F. Utilização de imagens aerofotográficas no mapeamento multitemporal do uso da terra e cobertura vegetal na bacia do rio Corumbataí - SP, com o suporte de sistemas de informações geográficas. In: Simpósio Brasileira de Sensoriamento Remoto, 13, 2007 Florianópolis (SC), Anais..., São José dos Campos - SP: INPE. Anais XIII SBSR, p. 1321-1328, 2007.

ROUSE, J. W.; HAAS, R. H. S.; SCHELL J. A.; DEERING D. W. Monitoring vegetation systems in the Great Plains with ERTS. In ERTS Symposium, 3., 1973. Proceedings... NASA, 1973, p. 309- 317.

SPAROVEK, G.: SCHNUG. E. Temporal Erosion-induced soil degradation and yield loss. Soil Science Society of American Journal, v. 65, n. 5, p. 1479-1486, 2001.

VALENTE, R. de O. A. Análise da estrutura da paisagem na Bacia do rio Corumbataí, SP. 2001.162 f. Dissertação (Mestrado em Recursos Florestais) - Escola Superior de Agricultura Luiz de Queiroz, Universidade de São Paulo, Piracicaba, 2001.

UNICA.União dos Plantadores de Cana-de-açúcar de São Paulo. Estatísticas do Setor Sucroalcooleiro. www.unica.com.br. Acesso em 06/03/2015.

WISCHMEIER, W. H. A rainfall erosion index for a universal soil-loss equation. Soil Science Society of America Proceedings, v.23, p.246-249, 1959.

WISCHMEIER, W.H.; SMITH, D.D. Predicting rainfall erosion losses: a guide to conservation planning. Washington: United States Department of Agriculture, 1978, 57 p. (Agriculture Handbook, n. 537). 